Original Research Article

\title{
Prescription errors in a tertiary care government hospital of eastern India: a preinterventional prospective study
}

\author{
Jeetendra Kumar*, Subhash Chandra, Hemant K. Sinha
}

\author{
Department of Pharmacology, \\ JLN Medical College, \\ Bhagalpur, Bihar, India \\ Received: 15 January 2017 \\ Accepted: 27 January 2017 \\ *Correspondence to: \\ Dr. Jeetendra Kumar, \\ Email: \\ drjktkhag2003@yahoo.co.in \\ Copyright: (C) the author(s), \\ publisher and licensee Medip \\ Academy. This is an open- \\ access article distributed under \\ the terms of the Creative \\ Commons Attribution Non- \\ Commercial License, which \\ permits unrestricted non- \\ commercial use, distribution, \\ and reproduction in any \\ medium, provided the original \\ work is properly cited.
}

\begin{abstract}
Background: Prescription errors are known to exert various detrimental effects to both the patient and the community. They are the commonest form of preventable medication errors. However, the concerned data was deficient for eastern part of our province due to inadequate efforts made in this area. This study therefore was carried out to generate the baseline data on the nature and extent of prescription errors prevalent in this part of our country so as to give remedial messages.

Methods: A pharmacy based cross sectional descriptive study of 731 randomly selected prescriptions of a government tertiary care hospital was done in a prospective manner. They were investigated for the legibility, core elements of a prescription and overall use of abbreviations.

Results: The total number of prescription errors were7626. The drug related errors constituted $65.72 \%$ and prescriber's related error constituted $34.28 \%$ of the total errors. Errors of omission were $77.72 \%$ and that of commission were $22.28 \%$. $11.9 \%$ prescriptions were illegible. The information, instructions and warnings were not mentioned on $72.09 \%$ prescriptions. Both the errors of omission and errors of commission were observed for strength of the nearly half of the prescribed medications. The route of administration and duration of treatment were the two most frequently omitted errors. Use of unauthorized abbreviations was also exercised for $28.18 \%$ of the prescribed medications.

Conclusions: Prescription errors of different types are common in our hospital. Prescribers need their special attention to take care the legibility of prescription, the use of authorized abbreviation, the route and duration of administration. The concept of computerized prescription can be adopted as intervention to minimise these errors.
\end{abstract}

Keywords: Government hospital, Legibility of prescription, Prescription errors, Tertiary care

\section{INTRODUCTION}

The most frequent therapeutic intervention offered to patients consequent to consultation with a clinician is the prescription. The prescription is a written order by the prescriber to the pharmacist to prepare or dispense a specific treatment usually a medication for specific patient. ${ }^{1}$ The prescription writing is the most crucial step in drug supply use chain that determines largely the outcome of a therapeutic intervention. Even the most carefully made therapeutic decision by the prescriber may become useless, if the prescription fails to communicate clearly the intent of the prescriber to the pharmacist and does not instruct the patient adequately regarding the use of prescribed medication. The errors occurred at this step can result in various detrimental effects like therapeutic failure, wastage of therapeutic resources, adverse clinical consequences and economic harm to both the patients and the community. Therefore, the prescriptions must be carefully prepared to identify the patient and the medication to be dispensed, as well as the manner in which the medication is to be administered. ${ }^{2}$ There is no global standard for prescriptions and every country has its own standards and regulations for the minimum informations to be contained on prescription as an essence. The World Health Organization (WHO) suggests the minimum set of informations as core elements to be mentioned on a prescription order to 
ensure good prescribing. ${ }^{3}$ Good prescribing implies the prescribing of the appropriate drug, in the correct dosage of an appropriate formulation, at the correct frequency of administration, and for the correct length of time.

Unfortunately, prescription errors are the commonest type of reported medication errors. ${ }^{1,5}$ Several international and national studies have reported regarding occurrence of prescription errors of different types and magnitudes. ${ }^{5-15}$ Prescription errors have been defined as a defect in the process of prescribing that results in an unintentional reduction in the probability of treatment being delivered in a timely and effective manner or increases the risk of harm from the medication. ${ }^{11}$ Errors of omission and errors of commission are two main types of described prescription errors. Errors of omission are where a prescription is incomplete in some way, whereas errors of commission contain incorrect information. ${ }^{8,13}$ Since prescription errors are the preventable forms of medication errors, there is a much scope for improvement in this area. It is imperative to define the nature and extent of the problem, before an attempt is made to improve it. Therefore, this study has been undertaken with an objective to generate the baseline data on the prevailing prescription errors and their nature and extent. The aim of this study also included to provide remedial messages to prescribers so that they can rectify their problems and thereby, can improve their performance in their practice.

\section{METHODS}

This was a cross sectional descriptive study conducted at Jawahar Lal Nehru Medical College hospital. This is a tertiary care teaching hospital run by government of Bihar located at Bhagalpur in eastern part of India. Patients were approached for their prescriptions at the nearby pharmacies on a fixed day in each week during the month September 2016. Patients were explained the purpose of this study and their consents were taken prior to get their prescriptions. Each of the prescription obtained in this way was photographed to record the contained information. Only freshly registered outpatients with their prescriptions belonging to all ages and both sex from all clinical departments were included to get the prospective data for this study. The data collection was done away from the outpatient clinics only at nearby pharmacies in a confidential manner to minimize the possible observational bias as per the guideline of WHO. $^{16}$ Prescriptions with instruction to indoor admission and that of follow up cases were not included in this study considering their complexity. Prescriptions with only advised investigations and/or some operative procedure without any drug prescription were also excluded from this study.

The data obtained by this method from 731 prescriptions were analyzed initially to exclude illegible prescriptions. Thereafter, the legible prescriptions were analyzed for the core elements under the guidelines of $\mathrm{WHO}{ }^{3}$ The core elements of prescriptions were categorized into the prescriber related information and the drug related information. The core elements included under the category prescriber related information were the legibility of prescription, prescriber's identity (Name, Department, Designation, Qualification, Registration and Contact Number), the date and place of prescription, the patient's identity (Name, Age, Sex, Address and OPD number), the diagnosis, the symbol of $\mathrm{Rx}$ or Advice, the prescriber's signature and the information, instructions and warnings to the patient.

Those included under drug related information were the name of drug, its formulation and strength, total quantity to be dispensed, quantity per administration, the route and the frequency of administration, the duration of treatment and the use of unauthorized abbreviation. The observed data was expressed in number and percentage.

\section{RESULTS}

Eighty seven (11.9\%) prescriptions out of 731 total prescriptions were illegible. Sixty six prescriptions were having only advised investigations and/or some operative procedures among 644 legible prescriptions. The number of drugs prescribed on remaining 578 prescriptions was 1643. The total number of detected errors was 7626 . Among these, the total number of prescriber related errors was $2614(34.28 \%)$ and drug related errors were $5012(65.72 \%)$. The total number of errors of omission was $5927(77.72 \%)$ and that of commission were 1699 (22.28\%). There were no any error related to patient's name, age, sex and registration number.

The date and place of prescription were mentioned on each prescription. The address of the patient was mentioned on all prescriptions, but in an incomplete and non-communicative manner. The qualification, medical council registration number and contact number of prescribers were not mentioned in any of the observed prescriptions. The name of prescriber along with the name of clinical department and the designation was stamped on majority of the prescriptions. The information, instructions and warnings were not mentioned on $72.09 \%$ of prescriptions. The errors in prescriber related information are detailed in Table 1.

There was no any error in the name of prescribed drug and the quantity to be given in one administration. However, route of administration were not mentioned for seventy five percent of prescribed medications. Both the errors of omission and commission were observed for the strength of prescribed drugs. Quantity to be dispensed was not mentioned for over $45 \%$ drugs. Duration of treatment was not stated for over sixty seven percent prescribed drugs. Unauthorized abbreviations were observed for $463(28.18 \%)$ drugs. The different types of drug related errors are detailed in Table 2. 
Table 1: Errors in prescriber related information $(n=731)$.

\begin{tabular}{|lllll|}
\hline S. No. & Component/Element & $\begin{array}{l}\text { No.(\%) of error of } \\
\text { omission }\end{array}$ & $\begin{array}{l}\text { No.(\%) of error } \\
\text { of commission }\end{array}$ & $\begin{array}{l}\text { Total no.(\%) } \\
\text { of errors }\end{array}$ \\
\hline 1. & Legibility of prescription & Nil (Zero) & $87(11.90)$ & $87(11.90)$ \\
\hline 2. & $\begin{array}{l}\text { Prescriber`s identity(Name, department and } \\
\text { designation) }\end{array}$ & $113(15.45)$ & Nil (Zero) & $113(15.45)$ \\
\hline 3. & $\begin{array}{l}\text { Qualification, registration no. and contact no. of } \\
\text { prescriber }\end{array}$ & $731(100)$ & Nil (Zero) & $731(100)$ \\
\hline 4. & Date and place of prescription & Nil (Zero) & Nil (Zero) & Nil (Zero) \\
\hline 5. & Patient`s identity & Nil (Zero) & Nil (Zero) & Nil (Zero) \\
\hline 6. & Patient`s address & Nil (Zero) & $731(100)$ & $731(100)$ \\
\hline 7. & Diagnosis/complaints & $150(20.51)$ & Nil (Zero) & $150(20.51)$ \\
\hline 8. & Symbol Rx/Adv & $177(24.21)$ & Nil (Zero) & $177(24.21)$ \\
\hline 9. & Prescriber`s signature & $98(13.40)$ & Nil (Zero) & $98(13.40)$ \\
\hline 10. & Information, Instructions and warnings to patient & $527(72.09)$ & Nil (Zero) & $527(72.09)$ \\
\hline 11. & Grand total & 1796 & 818 & 2614 \\
\hline
\end{tabular}

Table 2: Errors in Drug related information $(n=1643)$.

\begin{tabular}{|lllll|}
\hline S. No. & Component/Element & $\begin{array}{l}\text { No. }(\%) \text { of errors } \\
\text { of omission }\end{array}$ & $\begin{array}{l}\text { No. }(\%) \text { of errors of } \\
\text { commission }\end{array}$ & $\begin{array}{l}\text { Total no. }(\%) \text { of } \\
\text { errors }\end{array}$ \\
\hline 1. & Name of drug & Nil (Zero) & Nil (Zero) & Nil (Zero) \\
\hline 2. & Dosage form & $239(14.55)$ & $190(11.56)$ & $429(26.11)$ \\
\hline 3. & Strength of drug & $588(35.78)$ & $228(13.88)$ & $816(49.66)$ \\
\hline 4. & Quantity to be dispensed & $740(45.03)$ & Nil (Zero) & $740(45.03)$ \\
\hline 5. & Quantity per administration & Nil (Zero) & Nil (Zero) & Nil (Zero) \\
\hline 6. & Route of administration & $1233(75.04)$ & Nil (Zero) & $1233(75.04)$ \\
\hline 7. & Frequency of administration & $226(13.75)$ & Nil (Zero) & $226(13.75)$ \\
\hline 8. & Duration of treatment & $1105(67.25)$ & Nil (Zero) & $1105(67.25)$ \\
\hline 9. & Use of unauthorized abbreviations & Nil (Zero) & $463(28.18)$ & $463(28.18)$ \\
\hline 10. & Grand total & 4131 & 881 & 5012 \\
\hline
\end{tabular}

\section{DISCUSSION}

There is no any scope for an error of omission or that of commission on an ideal prescription paper. The omission or commission of any of the needed information could result in miscommunication in between a prescriber and a pharmacist and serious health outcomes in patients. Our study reveals a wide range of different types of prescription errors. At least one or more errors were observed on each prescription in our study. The zero percent error on writing elements like name, age and sex of the patient was because of the use of computer software. Absence of error in writing components like OPD registration number, the place and the date of prescription are also due to the same reason in our study. The analysed prescriptions were deficient regarding the complete address of patients. A full and complete address ensures the identity of a particular patient along with a well communication in between a pharmacist and a patient in the event of dispensing error. Prescriber's identity were only partial. The contact number of prescriber was not mentioned on any prescription. Security reason seems to be the contributing factor in this regard. However, a complete identity of prescriber is recommended to facilitate a timely contact by pharmacist in the event of confusion regarding the prescribed medication. We were not able to read the drug related content in $11.9 \%$ prescriptions due to poor handwriting of prescribers. Though its occurrence in our study is far less in comparison to that reported in study of Saudi Arabia $(64.3 \%)$ and less in comparison to that reported from Sudan (15.8\%) and Ethiopia (15\%), our figure in this concern is not better than those reported from Brazil $(6.6 \%)$ and Nepal $(0.63 \%){ }^{6,7,9,12,13}$ This is a matter of great concern, because badly handwritten prescriptions can lead to mistakes. Poor handwriting is a well known and preventable cause of dispensing error. ${ }^{2}$ The WHO emphasizes the clarity and legibility of prescriptions as the legal duty of the doctor. ${ }^{3}$ The prescription should indicate precisely what should be given, to avoid the occurrence of any medication error. Both the qualification and the medical council registration number of doctors were deficient in all the prescriptions under the study. This figure is almost comparable to that reported from Nepal, where $99.6 \%$ of prescriptions were also deficient in this component. ${ }^{13}$ This seems to be a common 
practice in government or institutional clinics most likely due to patient pressure. However, their importance should not be underestimated as they provide the legal identity to the prescriber and helps pharmacist to contact for clarification of any doubt. ${ }^{4}$

Diagnosis or at least complaints were not mentioned on $20.51 \%$ prescriptions in our study. This figure is less in comparison to those reported from Sudan (94\%) and Saudi Arabia (33.3\%). ${ }^{6,12}$ However, this particular element should be mentioned in all the prescriptions as this helps the pharmacist to dispense the right drug to the right patient. This is considered to be the single most important measure to prevent dispensing errors. ${ }^{2}$

Both errors of omission and commission were found in our study regarding strength of prescribed medications and their total frequency was $49.66 \%$. This figure is less in comparison to that reported from Saudi Arab (73.4\%) but not better than those reported from Nepal $(40.5 \%)$, Brazil (18.2\%), Ethiopia (5.8\%), Ireland (5\%) and Bahrain $(2.2 \%) .^{6,9,11,13,17,19}$ Such errors are also a potential source for dispensing errors and therefore should not be allowed to occur. Quantity to be dispensed was not mentioned for $45.03 \%$ of the prescribed drugs in our study. This is a better figure in comparison to those reported from Saudi Arabia (90.4\%) and Sudan $(59.7 \%))^{6,12}$ There should be a clear cut instruction to pharmacist regarding the amount of medication to be dispensed.

Route of administration was not stated for over threefourth $(75.04 \%)$ drugs in our study. The reported figure for this element from Nepal (62.6\%), Ireland (13\%), Ethiopia (12\%) and Brazil (7.2\%) are less in comparison to us. ${ }^{9,11,13,17}$ As absence of this element can lead to a major medication error, the prescribers in our hospital need special attention to rectify their habits for this important element and thereby to prevent such large scaled omission. Frequency of administration was missing for $13.75 \%$ drugs in our study. Though our figure is less in comparison to the report of Bahrain (19.9\%), but this is not better than those reported from Ireland $(11 \%)$ and Ethiopia $(6.4 \%) .{ }^{11,17,19}$ The duration or length of treatment was also one of the neglected elements in our study as it was not stated for $67.25 \%$ of the prescribed drugs. The reported figures for this element from Sudan $(25.7 \%)$, Bahrain $(18.5 \%)$ and Ethiopia $(1.6 \%)$ were far better than ours. ${ }^{12,17,19}$ The wide occurrence of this error warrants our physicians for rectification.

The information, instructions and warnings regarding the given treatment to patients was the most neglected component in all the analysed prescriptions. Patient pressure and prescribers ignorance regarding its significance seems to be the contributory factor for such error. Such errors can lead either to non-compliance with therapy as in case of anti-tuberculosis drugs or can lead to major hazards in the form of accidents as in case of treatment with sedative drugs. The WHO advocates for the proper information, instructions and warnings for the given drug treatment to patient. ${ }^{3}$ There is a need to give reminders to the prescribers of our hospital in this concern to rectify their practice.

Prescriber's signature was lacking in $13.4 \%$ prescriptions in our study. Prescriber's signature were lacking also in the studies of Saudi Arabia (19.1\%), Nepal (15.7\%), Sudan $(4.6 \%)$ and Ireland (2\%). ${ }^{6,11-13}$ Prescriber's signature is must to authenticate the prescription. ${ }^{4}$ Unauthorized abbreviations like PCM for Paracetamol, DFC for Diclofenac etc. were also noted in our study for $28.18 \%$ of the prescribed medications. This is almost comparable to the report from Nepal $(27.25 \%) .{ }^{13}$ Use of unauthorized abbreviations can misguide the pharmacist to dispense wrong medication. ${ }^{2,18}$ Only common and internationally accepted abbreviations should be used to prevent possible medication errors. ${ }^{3,4}$

\section{CONCLUSION}

This study reveals that though there are good practices in writing some of the elements, prescription errors of different types and magnitudes are also frequent. The elements that need special attention of prescribers are the legibility of prescription, the diagnosis, the prescriber's identity, the strength of prescribed drug, the route and the length of administration. The use of unauthorized abbreviations is also common and there is a need to discourage such practice in an order to minimize the dispensing errors and other bad health consequences of such inappropriate medical care. The concept of computerized prescription can be adopted as intervention to minimise these errors.

\section{ACKNOWLEDGEMENTS}

We sincerely acknowledge the hard work of our second professional medical students in due course of data collection for this study. We are thankful to all the pharmacy people of nearby pharmacy shops for their kind cooperation and patience during data collection. We extend our thanks to Md. Imrose Rana of our department for his technical assistance in preparing this manuscript.

Funding: No funding sources

Conflict of interest: None declared

Ethical approval: The study was approved by the Institutional Ethics Committee

\section{REFERENCES}

1. Lofholm PW, Katzung BG. Rational prescribing and prescription writing. In: Katzung BG, Trevor AJ, eds. Basic and clinical pharmacology. $13^{\text {th }}$ ed. New Delhi: McGraw Hill Education (India); 2015:1108-1117.

2. Buxton ILO. Principles of prescription order writing and patient compliance. In: Brunton LL, Chabner BA, Knollmann BC, eds. Goodman and Gilman's 
The Pharmacological Basis of Therapeutics. 12th ed. New York, NY: McGraw Hill; 2011:1879-1889.

3. DeVries TPGM, Henning RH, Hogerzeil HV, Fresle DA. Guide to good prescribing: A practical manual. Geneva: World Health Organization; 1994. WHO/DAP/94.11.

4. Grahame-Smith DG, Aronson JK. Oxford textbook of clinical pharmacology and drug therapy. $3^{\text {rd }}$ ed. New Delhi: Oxford University Press; 2008:173-188.

5. Lisby M, Nielsen LP, Mainz J. Errors in the medication process: frequency, type and potential. Int J Qual Health Care. 2005;17(1):15-22.

6. Irshaid YM, Homrany MA, Hamdi AA, AdjeponYamoah KK, Mahfouz AA. Compliance with good practice in prescription writing at outpatient clinics in Saudi Arabia. East Mediterr Health J. 2005;11(5/6):922-8.

7. Makonnen E, Yoseph M, Berhane Y. Quality of prescription at a tertiary care pharmacy in Addis Ababa. Ethiop Med J. 2002;40:233-9.

8. Nadeem S, Shah H, Aslam M, Avery AJ. A survey of prescription errors in general practice. Pharm J. 2001;267:860-2.

9. Silva AMS. Inpatients medical prescription errors. Einstein. 2009;7(3):290-4.

10. Sayers YM, Armstrong P, Hanley K. Prescribing errors in general practice: A prospective study. Eur J Gen Pract. 2009;15:81-3.

11. Bates K, Beddy D, Whirisky C, Murphy M, O'Mahony JB, Mealy K. Determining the frequency of prescription errors in an Irish hospital. Ir J Med Sci. 2010;179:183-6.

12. Yousif E, Ahmed AM, Abdalla ME, Abdelgadir MA. Deficiencies in medical prescriptions in a Sudanese hospital. East Mediterr Health J. 2006;12(6):915-8.
13. Ansari M, Neupane D. Study on determination of errors in prescription writing: A semi-electronic perspective. Kathmandu Univ Med J. 2009; 7(27):238-41.

14. Pote S, Tiwari P, D'Cruz S. Medication prescribing errors in a public teaching hospital in India: A prospective study. Pharmacy Practice. 2007;5(1):1720.

15. Volvoikar MH, Rataboli PV. Nature of prescribing and incidence of medication prescription errors in general practice. Int $\mathbf{J}$ of Pharmacol Research. 2016;6(7):238-43.

16. WHO. How to investigate drug use in health facilities: Selected drug use indicators. Geneva: World Health Organization; 1993. WHO/DAP/93.1.

17. Desta Z, Abdulwhab M. Prescription writing in Gondar outpatient teaching hospital, Ethiopia. East Afr Med J. 1996;73:115-9.

18. Dubey AK, Subish P, Shankar PR, Mishra P, Prabhu $\mathrm{M}$, Bhandari RM, et al. Introduction to medication errors and the error prevention initiatives in a teaching hospital in western Nepal. Pak. J. Pharm. Sci. 2006;19(3):244-51.

19. Al Khaja KAJ, Sequeria RP, Al-Ansari TM, Damanhori AHH. Prescription writing skills of residents in a family practice residency programme in Bahrain. Postgrad Med J. 2008;84:198-204.

Cite this article as: Kumar J, Chandra S, Sinha HK. Prescription errors in a tertiary care government hospital of eastern India: a preinterventional prospective study. Int J Basic Clin Pharmacol 2017;6:533-7. 